\title{
Title: Individual differences in faculty research time allocations across 13 countries
}

\author{
Peter James Bentley • Svein Kyvik
}

\begin{abstract}
In research universities, research time is often too scarce to satiate the wishes of all faculty and must be allocated according to guidelines and principles. We examine self-reported research hours for fulltime faculty at research universities in 13 countries (Argentina, Australia, Brazil, Canada, China, Finland, Germany, Italy, Malaysia, Norway, UK, USA, and Hong Kong, a semi-autonomous special administrative region of China). We examine the level of variation in individual faculty research time and the factors associated with individual differences, including differences in: (a) university policy regarding the allocation of working time for research between individual faculty members, (b) individual motivation towards research, and (c) family commitments. Our results suggest that the factors associated with additional research time vary across countries, but individual motivation towards research (relative to teaching) is a significant in all countries. University policies towards research and the research status of individual faculty, are relatively weak predictors of individual research time, though stronger effects are generally found in English-speaking countries. Research hours typically decrease with age, but plateau or increase in the oldest cohorts. Family and gender are weak predictors of research time amongst full-time faculty.
\end{abstract}

Keywords

Research time, research motivation, resource allocation, faculty work 


\section{Introduction}

University faculty perform a variety of work tasks with levels of autonomy rarely seen in other professions. However, professors do not have complete discretion over working time decisions as, amongst other institutionally regulated activities, professors are typically required to teach a minimum number of classes, supervise doctoral students and partake in administrative work. In line with general public sector reforms under the auspices of new public management (Hood 1995), managerial reforms have required universities to further justify the public investment of resources through greater transparency, accountability and efficiency. Faculty time is a core and valuable institutional resource. In research universities - where tenure, promotion, salary and prestige are closely related to research output research time is scarce and must be carefully managed.

Through the regulation of weekly teaching hours, yearly supervision hours, and other duties, universities control the availability of time remaining for research. However, faculty also differ in their research interest and non-work commitments. This affects their propensity to trade off discretionary research hours for non-work time. Therefore, research time is partly a residual category, based on time available after all other formally regulated contact hours, and partly discretionary, based on work and leisure trade-offs.

Academic workload studies typically examine the trade-offs in time use across activities and most former studies are single-country. Drawing international generalizations from national level studies is fraught with conceptual and theoretical complexities. Virtually all studies define faculty tasks and roles differently, or use different methods of data collection (Rosser and Tabata 2010; Meyer 1998). International studies indicate that the proportion and number 
of hours spent on research, teaching and other activities differs greatly across countries and between universities (Enders and Teicher 1997; Gottlieb and Keith 1997; Bentley and Kyvik 2012). While there are many reasons why faculty differ in their time use, most comparative studies are descriptive and do not analyze factors associated with working time patterns.

One exception is Gottlieb and Keith’s (1997) international study of research hours in Australia, Israel, South Korea, Sweden, West Germany, UK, Japan and USA. Through OLS regression, they analyzed the correlation between research hours and published articles, research/teaching orientation, total enrolment, total courses taught, academic rank, sex and teaching hours. The strongest factor associated with research hours was research orientation, followed by publications. Research oriented faculty spent one-third to two-thirds more hours on research compared to teaching orientated, while five additional publications (in the previous three years) were associated with one extra research hours per week.

The purpose of this study is to examine, from an international comparative perspective, the level of variation in individual faculty research time in research universities, and the factors associated with individual differences. Data on working time patterns of individual faculty members have been drawn from universities across 13 countries (Argentina, Australia, Brazil, Canada, China, Finland, Germany, Italy, Malaysia, Norway, UK, USA, and Hong Kong, a semi-autonomous special administrative region of China). Former multivariate studies from the United States and Australia indicate that research time is predominantly shaped by a combination of personal, family, career and institutional characteristics (Link et al. 2008; Singell et al. 1996; Guest and Duhrs 2002). Based on these studies and other former literature in this field, we propose three different groups of explanations for skewed patterns of research time, including differences in: (a) university policy regarding the allocation of 
working time for research between individual faculty members, (b) individual motivation towards research, and (c) family commitments. The international comparative dimension allows us to examine whether country specific results, such as those found previously in the USA and Australia, apply to a wider range of countries.

\section{Differences in university time allocation policy}

When organizational resources are too scarce to satiate the wishes of all recipients, limited resources must be allocated according to guidelines and principles. Previous studies of allocation of research time suggest that distributional allocation may be motivated by strategic and practical reasons, as well as by considerations on fairness (Kyvik, 2009). The strategic objectives of universities — which include multiple missions of research, teaching and service to the community — underpin the rationale for discretionary management of research time. If universities can identify individual faculty with the greatest potential for contributing towards institutional research goals, management can introduce policies and incentives that skew research time towards preferred recipients. Management can also indirectly shape research time allocation by linking human resource decisions with performance. This could include determining research funding and resource allocations based on research performance, or alternatively, encouraging some faculty to pursue non-research activities, such as entrepreneurial services.

However, strategic management of research time also involves transaction costs associated with evaluating research goals and negotiating individual work agreements. There are also considerations of fairness. Equal access to research time may be the fairest and least costly 
method, but fails to efficiently distribute the resource for greatest effect. Fairness and practical considerations tend to encourage research time allocation policies based on fixed standards, rather than managerial discretion. In practice, this can mean fixed standards for all faculty within certain easily perceptible status criteria. For example, it may be practical, fair and reasonably efficient to allocate greater research time to full professors, given that attaining professorship usually entails a strong prior research record. Regardless, such fixed standards may also be contentious, particularly if taken to an extreme where stratification across rank leaves inadequate access to research time in lower ranks and opportunities to demonstrate research competence.

As noted by Elster (1992), actual allocation systems can rarely be reduced to a single allocation principle or procedure. Allocation systems typically entail a combination of discretion, negotiation and fixed standards based on recipient status. We examine three resource allocation practices within the discretion of university management for steering research time towards strategic objectives: research funding, linking research quality to personnel decisions; and encouraging service/entrepreneurial activities. We also examine three easily perceptible status criteria: academic rank; doctoral qualifications; and research publishing record.

\section{Strategic objectives}

Across the world, decreases in guaranteed institutional and governmental funding for research make faculty increasingly dependent upon external research funding for "buying” research time. Strategic objectives of universities may not be directly aligned with external stakeholders, but faculty successful in gaining external funding wield disproportionate 
influence over university councils, often reshaping institutional missions in line with their funded objectives (Massy 2004). The ability to raise research funding stratifies faculty across disciplines and universities (Slaughter and Leslie 1997), with clear impacts on research performance. In an international study of factors associated with individual faculty research output across ten countries, level of research funding was one of the strongest and most frequently significant predictors of individual research output (Teodorescu 2000). Its impact was particularly strong in the English-speaking countries, where new public management and marketization have longer traditions. With research becoming increasingly tied to relevance and external stakeholders, a coping mechanism and unintended consequence of new public management has been increased specialization in teaching, research or administrative roles (Barry et al. 2003). In such circumstances, the signaling effect of research funding likely leads to a cumulative advantage for the recipients, further increasing their chances for blocks of research time in the future. The growing importance of external research funding leads us to expect faculty receiving most of their research funding from non-institutional sources, and those satisfied with their research funding, will spend more hours on research. We also expect the importance of research funding to be stronger in countries where marketization is more deeply embedded in research allocation systems, such as the English-speaking countries.

Not all universities place similar emphasis on a research mission or expect all faculty to engage primarily in research and teaching. The type of university to which one is employed (based on the Carnegie classifications) was the strongest predictor of time spent on research and service activities in the USA (Bellas and Toutkoushian 1999). Service-based and entrepreneurial activities, such as business ventures, professional lectures, and service or consulting for governments (local and worldwide), have varying degrees of value to the individual and the university. These activities encourage practical application of university 
research, raise additional revenue and legitimize the university's position in the stakeholder community. However, their engagement leaves less time for research, and if actively encouraged by the university, provide fewer incentives to engage in traditional, campusbased activities (Zemsky et al. 2006). Therefore, we expect that faculty in institutions emphasizing entrepreneurial activities will spend fewer hours on research.

\section{Fixed standards}

Allocating resources based on strategic objectives requires clearly defined allocation principles and implementation procedures. These procedures are typically more costly, complicated and time consuming than simply providing equal access to all. Differential treatment can also be controversial by conflicting with the normative ideals of a homogenous faculty workforce in equal pursuit of research and scholarship. Such norms are often reflected in union-negotiated collective agreements or laws governing faculty work. For example, in three of Australia’s Group of Eight research intensive universities (Adelaide, Monash and Sydney), collective agreements prescribe a standard 40-40-20 ratio for workload divisions between research, teaching and other duties. Applying equal apportionment of research time to all faculty, irrespective of individual status, can be partly justified because it avoids conflict and minimizes cost in the allocation process (Kyvik 2009). However, treating the faculty workforce as homogenous is clearly inconsistent with the strategic allocation that differentiates between individuals.

A compromise is to allocate resources based on fixed standards. Fixed standards differentiate between groups of faculty members by providing standard apportionment to all individuals with easily perceptible features. Access to research sabbaticals may also be available only to 
full professors or those with research qualifications or faculty with demonstrated research competence. Combined with a promotional system that directly (or indirectly) rewards research performance, such policies skew research time towards groups of recipients most likely to utilize the resources. However, given that allocation is group-based, fixed standards do not direct resources to preferred individuals. Professors may have greater research competence, but individual professors often have different motivations to conduct research aligned with the strategic objectives.

Multiple fixed standards, such as equal research time for all research-active faculty in professorial positions adds further specificity, but in turn leads to greater complexity and potential conflicts when implementing the criteria. Given the reciprocal relationship between rank, research competence, research qualifications and research funding, it is difficult to examine fixed standards in isolation to other factors. However, we may expect that fixed standards criteria which differentiate access to research time will be weaker in countries where the academic hierarchy is flatter. For example, in Norwegian universities, all ranks have equal job security and institutional expectations of research (Kyvik 2012). Opportunities to gain research qualifications are also comparably strong with doctoral research positions receiving salaries and conditions commensurate to public sector positions. This is in contrast to the USA where the tenure-track differentiates faculty and an "underclass" of part-timers who struggle to receive minimum wage (Jacobs 2004). A steep hierarchy also operates in Australia, where low ranked positions face increased managerial oversight (Lafferty and Fleming 2000), and many faculty are unable to gain the necessary research qualifications for further advancement (White 2004). Based on national differences in steepness of the hierarchy, we may expect a stronger relationship between research publications, rank, qualifications and research time, in countries with steeper academic hierarchies. 


\section{Differences in research motivation}

It is common knowledge that individual interest and motivation towards conducting research varies among faculty and can also change with career stage (Rosser and Tabata 2010). While the sources for motivational differences are numerous, we put forward two possible explanations: the "sacred spark" theory, and the theory of utility maximization.

The "sacred spark" theory

Some faculty may be more strongly motivated than others to dedicate time to research simply because they have an inner compulsion to do so. This explanation has been referred to as the “sacred spark” theory (Cole and Cole 1973). Research typically requires long periods of unpaid working time, but such activities can be extremely absorbing for those who find the activity satisfying. The level of autonomy faculty possess over their working time beyond relatively short classroom teaching and administrative hours provides the freedom to seek out activities of professional and personal attachment (Enders 2001).

While it may be tempting to generalize a natural affinity of faculty towards research, not all academics were drawn to the profession out of research interests. In Australia and other countries, the unification of former vocational and teaching oriented colleges into the university sector required teaching-focused faculty, who lacked both research qualifications and research interests, to become research active (White 2001). However, Enders and Teichler (1997) found that in many countries a significant minority of faculty held stronger 
interests in teaching compared to research, and differences in research interest partly explained the proportion of time spent by faculty on research.

Gottlieb and Keith (1997) also found research oriented faculty were more likely than teaching oriented faculty to view their research as complimentary to their teaching. This may be because they seek out different teaching assignments. Research oriented faculty taught courses with fewer student assessment requirements and more frequently at a graduate level, utilizing major papers and oral presentations as the main forms of assessment. These former studies lead us to expect a positive relationship between research interest, graduate teaching and total research hours.

The utility maximization theory

According to this theory, faculty will seek to maximize the utility of their time in terms of income, prestige or intrinsic outcomes (Stephan and Levin 1992). As promotion at universities, visibility and prestige in the scientific community are first and foremost dependent on published output, faculty will use as much time as possible for research. However, this will hold only as long as they believe that this activity will result in the expected status achievement. Therefore, differences in research hours partly reflect differences in the perceived utility of additional research hours. For example, eminent researchers may experience diminishing marginal returns for additional research, given their already strong record. Well established researchers may perceive greater career or intrinsic benefits from other activities, such as consulting, external service and administrative leadership. Accordingly, it can be expected that older academics will use less time for research (Kyvik and Olsen 2008). 
The perceived utility of additional research also depends upon the belief that research is valued at one’s institution. Most research universities could be expected to include research quality in their personnel decisions, but the extent to which this is perceived to be the case will vary across institutions and countries. For example, in the United States the tenure process explicitly requires early-career faculty to exert a strong emphasis on research, while mid- and late-career faculty generally receive fewer research incentives. Link and colleagues (2008) found that tenure was significantly associated with individual research hours. Assistant professors in their first two years spent the greatest number of hours on research, while gaining tenure was associated with significantly fewer research hours. Importantly, the tenure process also fragmented the faculty below the full-professor rank. Faculty who had spent more than seven years as associate professor spent increasingly fewer hours on research. The perceived heavy workload requirements and minimal chances for successful tenure in top-tier American research universities, also discourages some capable researchers from the tenure track (Jacobs 2004). This results in an increasingly selective and research focused tenure-track professoriate. Overall, we expect that faculty who strongly believe that research is critical to human resource decisions will spend greater time on this activity.

\section{Differences in family commitments}

Caring responsibilities limit total working hours (Bellas and Toutkoushian 1999), particularly for female primary caregivers (Probert 2005). The self-directed nature of research time should be relatively compatible with domestic responsibilities because some work can be completed from home. For example, women at English universities are more likely than men to accommodate unpaid working hours by taking work home (Barry, et al. 2003). However, it 
may be difficult for women to maintain a research focus when interrupted with domestic responsibilities. Previous studies indicate that the impact of children on research publications is mixed (Creamer 1998) or minor (Sax et al. 2002). A stronger negative effect has been found for women with young children (Kyvik and Teigen 1996) and increasing with the number of children (Long 1990). The greater effect for female faculty is likely due to reduced total hours. When faced with competing demands, research often receives lowest priority for primary caregivers (Barry, et al. 2003; Probert 2005). Therefore, we expect the number of children in the home to be negatively associated with research hours.

\section{Data}

The data for this study comes from the Changing Academic Profession (CAP) international survey conducted in 2007/2008 among university faculty in 18 countries. This study is restricted to a subsample of full-time faculty in combined research and teaching positions at research universities. Therefore, all faculty with part-time contracts, less than 30 hour per week, or less than one hour per week on both teaching and research activities, were removed from the subsample. Institutional restrictions differed according to national classifications, but in most cases research universities were universities that offer post-graduate qualifications . However, there may be great differences in research capacity between research universities, particularly in unified higher education systems, such as Australia and the UK. Individual faculty were classified into five academic fields (social science, humanities, natural sciences, technology and medicine) based on the UNESCO (1978) guidelines. Five countries were removed from the subsample due to low response rates (below 10 percent in Korea and Portugal), unavailability of working time data (Mexico), incomplete sampling details (South Africa) and small sample of research university faculty 
(Japan). Prior to the weighting procedure, this left a sample of 7,117 faculty from 13 countries: Argentina, Australia, Brazil, Canada, China, Finland, Germany, Hong Kong, Italy, Malaysia, Norway, UK and USA.

National samples were considered representative of their respective populations on strata such as gender and institutional type, but full professors were over-represented in 10 countries (the exceptions being Italy and Malaysia, while no suitable population data was available on this stratum in Brazil). Given the consistency across countries, national samples were weighted based on academic rank for the 12 countries with suitable population data. The weighting was applied to the national samples, prior to subsample restrictions. Faculty excluded from the subsample were more likely to be of lower rank, and because lower ranked faculty were typically allocated a weighting of greater than one (due to over representation of full-professors in most national samples), the weighted sub-samples $\left(\mathrm{n}_{\mathrm{w}}\right)$ were generally smaller than the unweighted sub-samples (n). Response rates, the size of the national subsamples and the weighted subsamples are shown in Table 1. 
Table 1. Number of survey invitations to university faculty members; number of surveys returned; response rate, subsample (n) and subsample weighted for academic rank $\left(\mathrm{n}_{\mathrm{w}}\right)$

\begin{tabular}{|c|c|c|c|c|c|}
\hline & Surveys sent & Surveys returned & Response rate & $\mathrm{n}$ & $\mathrm{n}_{\mathrm{w}}$ \\
\hline Argentina & 2,400 & 826 & $34 \%$ & 371 & 328 \\
\hline Australia & 5,496 & 1,381 & $25 \%$ & 526 & 514 \\
\hline Brazil & 4,702 & 1,200 & $26 \%$ & 229 & 229 \\
\hline Canada & 6,693 & 1,152 & $17 \%$ & 702 & 705 \\
\hline China & 4,200 & 3,612 & $86 \%{ }^{a}$ & 429 & 395 \\
\hline Finland & 3,902 & 1,115 & 290 & 393 & 336 \\
\hline Germany & 3,891 & 1,246 & $\mathrm{a}$ & 612 & 521 \\
\hline Hong Kong & 6,219 & 811 & $13 \%$ & 527 & 365 \\
\hline Italy & 4,797 & 1,701 & $35 \%$ & 1,358 & 1,366 \\
\hline Malaysia & 4,114 & 1,226 & $30 \%{ }^{a}$ & 316 & 318 \\
\hline Norway & 2,883 & 1,035 & $36 \%$ & 366 & 276 \\
\hline UK & 11,000 & 1,663 & $15 \%^{\mathrm{a}}$ & 569 & 426 \\
\hline USA & 3,732 & 848 & $23 \%$ & 687 & 647 \\
\hline All countries & 64,029 & 17,816 & $28 \%$ & 7,117 & 6,459 \\
\hline
\end{tabular}

${ }^{\mathrm{a}}$ Response rate includes a small number of universities without combined teaching and research missions, excluded from the subsample.

The relatively low response rates of the CAP survey in many countries may reflect the general increase in the number of surveys academics receive, combined with other accountability procedures academics must respond to. It is difficult to estimate any potential biases in the CAP samples resulting from low response rate. Intuitively it may be reasonable to assume that academics most pressed for time and working the longest hours would more 
likely be non-respondents (thus underestimating overall working hours). However, there is less reason to assume that he relative time spent on research would be related to survey response.

The differences across countries in response rate to the CAP survey are probably due to combination of factors related to the sampling and distribution. Response rates were typically higher in those countries where both paper and online surveys were delivered to respondents (Finland, Germany, Italy, Norway, USA), compared to online-only (Argentina, Australia, Brazil, Canada, UK) or paper-only surveys (China, Malaysia, Hong Kong). Multiple formats for survey delivery increase the likelihood that the respondents receive the survey invitation and allow choice of preferred completion method. Online surveys may be particularly problematic in this regard due to the potential for unsolicited email invitations to be filtered (spammed) into the junk email folders. The exceptionally high response of the CAP survey in China is probably due to the high level of coordination in its survey distribution. The Chinese team also used gifts for university human resource officials assigned to deliver the survey, and for individual respondents.

\section{Methodology and variable summary}

Our dependent variable is the weighted average of self-reported individual weekly research hours in the teaching and non-teaching periods. The CAP survey categorized faculty workloads across five activities: teaching (preparation of instructional materials and lesson plans, classroom instruction, advising students, reading and evaluating student work), research (reading literature, writing, conducting experiments, fieldwork), service (service to clients and/or patients, unpaid consulting, public or voluntary services), administration 
(committees, department meetings, paperwork), and other academic activities (professional activities not clearly attributable to any of the categories above). Faculty reported typical weekly hours for two separate time periods: when classes are in session and when classes are not in session.

We annualize research hours by combining the two separate periods and weight the teaching period as twice the duration of the non-teaching period. Therefore, if one reports 15 research hours per week when classes were in session, and 30 research hours per week when classes were not in session, the weighted average for this individual is 20 research hours ([(15 hours * 2) +30 hours] / 3). To minimize outlier effects, total working hours are capped at 70 hours and research hours are reduced proportionally (further details on this approach: Bentley and Kyvik 2012).

Self-reported working hours have some clear limitations. Firstly, there may be errors of recall. Secondly, distinguishing between work and non-work time may be particularly challenging for faculty due to the highly flexible and autonomous substance of their work and daily schedules (Jacobs and Winslow 2004b). Thirdly, self-reports might lead to over-report of working time (Robinson and Bostrom 1994). In addition, there are often no clear-cut division between research and other tasks, like supervision of postgraduate students which contains elements of both teaching and own research. However, Jacobs (1998) found no systemic bias between self-reports and documented arrival and departure times. The aforementioned methodological problems are also of less concern in this study because we examine relative differences in research time between individuals. 
Differences across countries in mean research hours were statistically significant (ANOVA, $p<0.05)$. Therefore, we also applied post-hoc tests for significant differences between individual countries (Games-Howell ANOVA, $p<0.05$ ). Our choice of a Games-Howell posthoc test was based on unequal group sizes and variances (Jaccard et al. 1984).

Research hours were then modeled using OLS linear multiple regression. To help normalize the distribution, we used a log transformation. We checked for multicolinearity between independent variables by examining the variance inflation factors (VIF) for all 13 countries. Multicolinearity does not appear to be a problem as VIF values for the independent variables rarely reached 4, except in certain academic fields in China and Malaysia. ${ }^{1}$ To avoid multicolinearity between our two age-based variables, we centered age around the sample mean (by subtracting 48 years from an individual's age. Our independent variables were categorized and operationalized in the following way:

Differences in research time allocation policy: Strategic objectives

(a) Research funding satisfaction: A five point scale career variable is constructed from ordinal responses to satisfaction with research funding (poor=1; excellent=5).

(b) External research funding: A categorical variable for those who receive the majority of their research funding from outside their own university (no=0; yes=1).

(c) Entrepreneurialism: A five point scale variable based on the extent to which one's institution emphasizes “... academics to adopt service activities/entrepreneurial activities outside the institution" (not at all=0; very much=5).

Differences in research time allocation policy: Fixed standards

\footnotetext{
${ }^{1}$ China for Social Sciences (VIF=4.46), Natural sciences (VIF=5.92), and Technology (VIF=5.31); Malaysia for Social sciences (VIF=4.64), Natural sciences (VIF=5.78) and Technology (VIF=6.65).
} 
(d) Professor: A categorical variable based on holding the highest national academic rank (no=0; yes=1).

(e) $P h D:($ no=0; yes=1).

(f) Publications: Three categorical variables based on a weighted sum of self-reported authored books (4 points), edited books (1 point) and journal articles or book chapters (1 point) during the three years prior to the survey. Faculty were ranked and categorized as: highly publishing (top quartile); moderate publishing (middle two quartiles); or low publishing (bottom quartile).

Differences in research motivation: Sacred spark theory

(a) Research interest: A categorical variable based on a Likert scale response for interest in research relative to teaching (Primarily in teaching $=1$; In both, but leaning towards teaching $=2$, In both, but leaning towards research $=3$; Primarily in research $=4)$.

(b) Doctoral Teaching: A scale variable based on the proportion of teaching responsibilities devoted to doctoral programs.

Differences in research motivation: Utility maximizing theory

(a) Age: A scale variable centered around the sample mean (age-48 years).

(b) Age squared

(c) Research quality in personnel decisions: A five point scale variable based on the extent to which one’s institution emphasizes “... research quality when making personnel decisions” (not at all=0; very much=5).

(d) Tenure: (permanent contract of employment=1; non-permanent=0).

Differences in family commitments

(a) Sex: (female=0; male=1). 
(b) Children at home: Four categorical variables based on the number of children living at home: no children; one child; two children; three or more children (no=0; yes=1).

\section{Results}

The results summarized in Table 2 show individual faculty across the 13 country sample spent, on average, 18.5 hours per week on research or 39 percent of their total working hours on this activity. A relatively high standard deviation of 9.7 hours, indicated that individual research hours varied considerably between individuals. Consistent across all countries, most faculty reported research hours below the mean, as indicated by the relatively lower median research hours. Such a pattern is indicative of the skewed nature of research time, whereby a minority of faculty reported a large number of research hours. Differences in mean research hours between individual countries were statistically significant in most cases. Even the USA, the median country with an average of 17.6 research hours per week, differed significantly from six of the twelve other countries (ANOVA Games-Howell multiple comparisons $t$-test, $p<0.05)$. 
Table 2. Research hours per week: mean, median, standard deviation and as a percent of total hours, by country

\begin{tabular}{|c|c|c|c|c|c|c|}
\hline Country & Mean & Median & SD & $\%$ & $\mathrm{n}$ & $\mathrm{n}_{\mathrm{w}}$ \\
\hline Argentina & 21.8 & 20.7 & 8.3 & 50.3 & 371 & 328 \\
\hline Australia & 16.5 & 14.0 & 10.2 & 33.9 & 526 & 514 \\
\hline Brazil & 16.3 & 15.0 & 8.6 & 38.2 & 229 & 229 \\
\hline Canada & 20.4 & 18.7 & 9.2 & 40.8 & 702 & 705 \\
\hline China & 21.6 & 20.0 & 11.6 & 44.3 & 429 & 395 \\
\hline Finland & 16.6 & 14.7 & 9.0 & 35.9 & 393 & 336 \\
\hline Germany & 22.5 & 21.7 & 11.5 & 45.3 & 612 & 521 \\
\hline Hong Kong & 19.6 & 18.3 & 10.9 & 37.6 & 527 & 365 \\
\hline Italy & 21.6 & 20.0 & 9.6 & 46.3 & 1,358 & 1,366 \\
\hline Malaysia & 12.2 & 11.6 & 6.8 & 26.5 & 316 & 318 \\
\hline Norway & 17.6 & 16.7 & 8.9 & 36.8 & 366 & 276 \\
\hline UK & 16.5 & 14.1 & 10.2 & 34.0 & 569 & 426 \\
\hline USA & 17.6 & 16.0 & 11.0 & 35.8 & 687 & 647 \\
\hline Total (weighted mean) & 18.5 & 17.0 & 9.7 & 38.9 & 7,085 & 6,426 \\
\hline
\end{tabular}

Based on former academic workload studies, we hypothesized that individual differences in research hours may be due to three factors: university policies on the allocation of research time, individual motivation and family commitments. We also controlled for the effect of academic field. Our regression results in Table 3 show the relative effect of each independent variable in explaining variation in (log transformed) research hours among individual faculty members, with the humanities and childless faculty as the reference categories. We report both the unstandardized beta (B) and the standardized beta (Beta) coefficients. Based on the 
adjusted R-square, the model explained 34 percent of the variation in individual research hours in the Argentina and USA samples, with similar results in Australia (30 percent), the UK (29 percent), Germany (24 percent), and Canada (23 percent). However, substantially less variation was explained in Brazil (18 percent) Finland (17 percent), China (16 percent), Italy (15 percent) and Malaysia (12 percent). 
Table 3. OLS linear regression model explaining (log transformed) research hours

\begin{tabular}{|c|c|c|c|c|c|c|c|c|c|c|c|c|c|c|}
\hline & ARG & & AU & & BRA & & CAN & & $\mathrm{CHI}$ & & FIN & & GER & \\
\hline & B & Beta & B & Beta & B & Beta & $\mathrm{B}$ & Beta & B & Beta & B & Beta & B & Beta \\
\hline (Constant) & $2.29 * * *$ & & $1.63 * * *$ & & $2.70^{* * *}$ & & $1.87 * * *$ & & $2.56 * * *$ & & $1.81 * * *$ & & $1.95 * * *$ & \\
\hline Strategic objectives & & & & & & & & & & & & & & \\
\hline Research funding & $0.04 * *$ & $0.10 * *$ & $0.05^{* *}$ & $0.10^{* *}$ & 0.00 & 0.01 & $0.03 *$ & $0.07 *$ & 0.04 & 0.07 & -0.01 & -0.01 & $0.06 * *$ & $0.11^{* *}$ \\
\hline External res. & 0.03 & 0.03 & $0.16^{* * *}$ & $0.13^{* * *}$ & -0.11 & -0.06 & -0.01 & -0.01 & 0.11 & 0.09 & -0.13 & -0.11 & 0.02 & 0.02 \\
\hline Entrepreneurialism & -0.02 & -0.05 & 0.01 & 0.01 & -0.06 & -0.11 & 0.01 & 0.01 & -0.01 & -0.03 & -0.01 & -0.02 & 0.01 & 0.02 \\
\hline Fixed standards & & & & & & & & & & & & & & \\
\hline Professors & -0.07 & -0.06 & -0.12 & -0.06 & 0.04 & 0.02 & 0.08 & 0.07 & -0.09 & -0.08 & -0.06 & -0.05 & -0.04 & -0.02 \\
\hline $\mathrm{PhD}$ & $0.12 * *$ & $0.15^{* *}$ & $0.14 *$ & $0.09 *$ & -0.19 & -0.10 & $0.39 * * *$ & $0.18^{* * *}$ & 0.07 & 0.07 & -0.07 & -0.05 & -0.06 & -0.04 \\
\hline Low publishing & 0.05 & 0.06 & $-0.12 *$ & $-0.09 *$ & $-0.28 * *$ & $-0.22 * *$ & $-0.10 * *$ & $-0.10 * *$ & $-0.28^{* *}$ & $-0.16 * *$ & -0.06 & -0.04 & -0.09 & -0.07 \\
\hline High publishing & -0.05 & -0.05 & $0.27 * * *$ & $0.17 * * *$ & -0.06 & -0.05 & 0.03 & 0.02 & 0.11 & 0.10 & 0.14 & 0.10 & 0.00 & 0.00 \\
\hline Sacred-spark theory & & & & & & & & & & & & & & \\
\hline Research interest & $0.26 * * *$ & $0.38 * * *$ & $0.23^{* * *}$ & $0.28 * * *$ & $0.15^{* * *}$ & $0.17^{* * *}$ & $0.19 * * *$ & $0.28 * * *$ & $0.18^{* *}$ & $0.22 * *$ & $0.29 * * *$ & $0.35 * * *$ & $0.26 * * *$ & $0.32 * * *$ \\
\hline Doctoral teaching & $0.00^{* *}$ & $0.13^{* *}$ & $0.00 *$ & $0.10^{*}$ & $0.01 * * *$ & $0.23 * * *$ & 0.00 & -0.04 & 0.00 & -0.03 & $0.00 *$ & $0.13 *$ & $0.00 *$ & $0.10^{*}$ \\
\hline Utility maximizing & & & & & & & & & & & & & & \\
\hline Age & $-0.01 * *$ & $-0.12^{* *}$ & 0.00 & -0.07 & 0.00 & -0.02 & $-0.01 * * *$ & $-0.16 * * *$ & 0.01 & 0.09 & 0.00 & -0.02 & 0.00 & 0.01 \\
\hline Age squared & $0.00 * *$ & $0.11^{* *}$ & 0.00 & 0.03 & 0.00 & 0.08 & 0.00 & -0.07 & 0.00 & 0.01 & 0.00 & 0.11 & 0.00 & 0.00 \\
\hline Research quality & $-0.05^{* * *}$ & $-0.14 * * *$ & 0.00 & -0.01 & -0.05 & -0.11 & 0.01 & 0.02 & 0.02 & 0.05 & 0.06 & 0.10 & 0.03 & 0.05 \\
\hline Tenured $^{\mathrm{a}}$ & $-0.15 *$ & $-0.08 *$ & $-0.15 * *$ & $-0.12 * *$ & -0.02 & -0.01 & $-0.09 *$ & $-0.09 *$ & -0.10 & -0.07 & -0.01 & -0.01 & -0.02 & -0.02 \\
\hline Family commitments & & & & & & & & & & & & & & \\
\hline Male & -0.05 & -0.06 & $0.10^{*}$ & $0.08 *$ & -0.05 & -0.04 & 0.06 & 0.06 & 0.13 & 0.11 & -0.08 & -0.06 & 0.02 & 0.01 \\
\hline One child & 0.05 & 0.05 & 0.03 & 0.02 & -0.02 & -0.02 & -0.03 & -0.02 & $-0.18 *$ & $-0.16^{*}$ & -0.17 & -0.10 & -0.10 & -0.06 \\
\hline Two children ${ }^{\mathrm{b}}$ & 0.04 & 0.04 & -0.03 & -0.02 & 0.07 & 0.06 & 0.03 & 0.02 & N/A & N/A & -0.01 & -0.01 & $-0.22 * * *$ & $-0.14^{* * *}$ \\
\hline Three children ${ }^{\mathrm{b}}$ & -0.02 & -0.02 & -0.12 & -0.06 & -0.14 & -0.06 & 0.07 & 0.04 & N/A & N/A & -0.11 & -0.06 & 0.02 & 0.01 \\
\hline Academic field & & & & & & & & & & & & & & \\
\hline Social sciences & $-0.13^{*}$ & $-0.12 *$ & -0.01 & 0.00 & 0.14 & 0.10 & $0.09 *$ & $0.09 *$ & $-0.34 * *$ & $-0.25 * *$ & -0.04 & -0.03 & 0.02 & 0.02 \\
\hline Natural sciences & -0.06 & -0.06 & 0.06 & 0.02 & 0.09 & 0.04 & 0.02 & 0.01 & -0.15 & -0.13 & -0.14 & -0.07 & -0.08 & -0.05 \\
\hline Technology & 0.03 & 0.03 & 0.10 & 0.06 & $0.25^{* *}$ & $0.20^{* *}$ & $0.13 * *$ & $0.11^{* *}$ & -0.10 & -0.08 & 0.05 & 0.03 & $0.29 * * *$ & $0.21^{* * *}$ \\
\hline Medicine & $-0.15^{*}$ & $-0.10^{*}$ & 0.03 & 0.02 & -0.10 & -0.07 & 0.01 & 0.01 & -0.14 & -0.05 & -0.07 & -0.04 & -0.09 & -0.05 \\
\hline R-Square & 0.38 & & 0.34 & & 0.26 & & 0.26 & & 0.25 & & 0.25 & & 0.28 & \\
\hline Adjusted R-Square & 0.34 & & 0.30 & & 0.18 & & 0.23 & & 0.16 & & 0.17 & & 0.24 & \\
\hline n (weighted) & 306 & & 375 & & 197 & & 531 & & 176 & & 227 & & 362 & \\
\hline n & 348 & & 386 & & 197 & & 533 & & 209 & & 272 & & 450 & \\
\hline
\end{tabular}

${ }^{\mathrm{a}}$ All Italian faculty members are tenured. ${ }^{\mathrm{b}}$ All Chinese faculty with children were merged into the 'One child' category Reference categories: No children and Humanities 
Table 3. OLS linear regression model explaining (log transformed) research hours (continued)

\begin{tabular}{|c|c|c|c|c|c|c|c|c|c|c|c|c|}
\hline (Constant) & $\begin{array}{l}\mathrm{HK} \\
\mathrm{B} \\
1.91^{* * *}\end{array}$ & Beta & $\begin{array}{l}\text { ITA } \\
\mathrm{B} \\
2.57 * * *\end{array}$ & Beta & $\begin{array}{l}\text { MAL } \\
\text { B } \\
2.00^{* * *}\end{array}$ & Beta & $\begin{array}{l}\text { NOR } \\
\text { B } \\
1.96 * * *\end{array}$ & Beta & $\begin{array}{l}\mathrm{UK} \\
\mathrm{B} \\
1.29 * * *\end{array}$ & Beta & $\begin{array}{l}\text { USA } \\
\mathrm{B} \\
1.80^{* * *}\end{array}$ & Beta \\
\hline \multicolumn{13}{|l|}{ Strategic objectives } \\
\hline Research funding sat. & 0.00 & 0.00 & 0.01 & 0.01 & -0.04 & -0.07 & 0.02 & 0.05 & 0.03 & 0.04 & 0.02 & 0.04 \\
\hline External res. funding & 0.08 & 0.06 & $-0.07^{* *}$ & $-0.06 * *$ & -0.01 & -0.01 & -0.03 & -0.03 & 0.02 & 0.02 & 0.09 & 0.07 \\
\hline Entrepreneurialism & -0.05 & -0.08 & -0.01 & -0.01 & -0.07 & -0.11 & $-0.05^{*}$ & $-0.10 *$ & 0.02 & 0.03 & 0.01 & 0.01 \\
\hline \multicolumn{13}{|l|}{ Fixed standards } \\
\hline Professors & -0.09 & -0.06 & -0.02 & -0.02 & $-0.30 * *$ & $-0.15^{* *}$ & $0.15 *$ & $0.14 *$ & 0.05 & 0.03 & 0.04 & 0.03 \\
\hline $\mathrm{PhD}$ & 0.08 & 0.03 & 0.00 & 0.00 & 0.15 & 0.12 & 0.03 & 0.02 & 0.12 & 0.06 & 0.12 & 0.05 \\
\hline Low publishing & $-0.36 * * *$ & $-0.26 * * *$ & $-0.08 *$ & $-0.05^{*}$ & 0.02 & 0.01 & -0.10 & -0.09 & $-0.16 *$ & $-0.11 *$ & $-0.18 * * *$ & $-0.15^{* * *}$ \\
\hline High publishing & 0.09 & 0.06 & 0.03 & 0.03 & 0.00 & 0.00 & 0.13 & 0.11 & $0.33^{* * *}$ & $0.20 * * *$ & 0.02 & 0.01 \\
\hline \multicolumn{13}{|l|}{ Sacred-spark theory } \\
\hline Research interest & $0.24^{* * *}$ & $0.27 * * *$ & $0.19 * * *$ & $0.23 * * *$ & $0.31^{* * *}$ & $0.31 * * *$ & $0.21 * * *$ & $0.27^{* * *}$ & $0.32 * * *$ & $0.34 * * *$ & $0.32 * * *$ & $0.39 * * *$ \\
\hline Doctoral teaching & 0.00 & 0.06 & 0.00 & -0.03 & 0.00 & -0.09 & N/A & N/A & 0.00 & -0.02 & 0.00 & -0.03 \\
\hline \multicolumn{13}{|l|}{ Utility maximizing } \\
\hline Age & -0.01 & -0.09 & 0.00 & -0.06 & 0.01 & 0.20 & 0.00 & -0.04 & $-0.01 * *$ & $-0.16 * *$ & $-0.01 * * *$ & $-0.19 * * *$ \\
\hline Age squared & $0.00 * *$ & $0.14 * *$ & $0.00 * * *$ & $0.10 * * *$ & 0.00 & 0.07 & 0.00 & 0.05 & $0.00 *$ & $0.10^{*}$ & $0.00 * * *$ & $0.17 * * *$ \\
\hline Research quality & 0.03 & 0.05 & $-0.04 * * *$ & $-0.09 * * *$ & 0.02 & 0.04 & -0.02 & -0.04 & 0.04 & 0.07 & -0.01 & -0.02 \\
\hline Tenured $^{\mathrm{a}}$ & -0.10 & -0.08 & N/A & N/A & -0.21 & -0.11 & 0.08 & 0.04 & -0.12 & -0.06 & -0.07 & -0.06 \\
\hline \multicolumn{13}{|l|}{ Family commitments } \\
\hline Male & 0.13 & 0.09 & -0.01 & -0.01 & $0.20 * *$ & $0.16^{* *}$ & 0.04 & 0.03 & 0.13 & 0.10 & 0.00 & 0.00 \\
\hline One child & 0.01 & 0.01 & -0.03 & -0.02 & -0.09 & -0.06 & 0.02 & 0.01 & 0.03 & 0.02 & 0.10 & 0.06 \\
\hline Two children ${ }^{\mathrm{b}}$ & 0.00 & 0.00 & -0.02 & -0.02 & -0.08 & -0.06 & -0.13 & -0.10 & -0.05 & -0.03 & -0.02 & -0.01 \\
\hline Three children ${ }^{\mathrm{b}}$ & 0.06 & 0.02 & 0.00 & 0.00 & -0.02 & -0.01 & $-0.24 *$ & $-0.13^{*}$ & 0.22 & 0.08 & 0.18 & 0.06 \\
\hline \multicolumn{13}{|l|}{ Academic field } \\
\hline Social sciences & $0.17 *$ & $0.13 *$ & $-0.10 *$ & $-0.08 *$ & -0.01 & 0.00 & 0.12 & 0.10 & 0.08 & 0.06 & -0.06 & -0.05 \\
\hline Natural sciences & 0.13 & 0.06 & -0.07 & -0.05 & -0.16 & -0.12 & -0.01 & -0.01 & 0.13 & 0.06 & 0.10 & 0.05 \\
\hline Technology & 0.20 & 0.12 & 0.04 & 0.04 & 0.00 & 0.00 & $0.19 * *$ & $0.16^{* *}$ & -0.03 & -0.02 & $0.16 *$ & $0.10 *$ \\
\hline Medicine & 0.07 & 0.04 & $-0.40 * * *$ & $-0.25^{* * *}$ & $-0.35^{* *}$ & $-0.17 * *$ & 0.11 & 0.08 & -0.16 & -0.09 & $-0.17^{*}$ & $-0.09 *$ \\
\hline R-Square & 0.26 & & 0.17 & & 0.22 & & 0.27 & & 0.35 & & 0.37 & \\
\hline Adjusted R-Square & 0.19 & & 0.15 & & 0.12 & & 0.20 & & 0.29 & & 0.34 & \\
\hline n (weighted) & 245 & & 1094 & & 186 & & 233 & & 241 & & 415 & \\
\hline $\mathrm{n}$ & 373 & & 1087 & & 184 & & 317 & & 339 & & 471 & \\
\hline
\end{tabular}

${ }^{* * *} \mathrm{p}<0.01 ; * * \mathrm{p}<0.05 ;{ }^{*} \mathrm{p}<0.10$

a All Italian faculty members are tenured. ${ }^{b}$ All Chinese faculty with children were merged into the 'One child' category

Reference categories: No children and Humanities 
The independent variables addressing different institutional strategies for allocating resources generally did not explain a significant proportion of variation in individual research hours in most countries. However, there were some significant results in certain countries. The extent to which one was satisfied with research funding was positively associated with research hours in Australia, Argentina, Germany and Canada, but its relationship is relatively weak. For example, in Germany, a one-unit increase in satisfaction with research funding corresponded with a 6 percent increase in research hours. External research funding had little relationship with research hours, except in Australia where this was the third-strongest predictor of research time. Australian faculty who received most of their research funding from outside their own institution reported 16 percent more research hours. A small but significant negative relationship was also found in the Italian sample. The extent to which one’s university encouraged service and entrepreneurial activities had negligible relationship with research hours.

Results for Allocation based on Fixed standards

Our model included three easily perceptible status criteria for which universities may use to allocate additional research time: academic rank (full professorship); research qualifications (PhD) and recent publishing record (low, moderate and highly publishing). Professorship was a very weak predictor of research time, which may be surprising considering in most countries professors report more hours on research than lower ranked staff (Bentley and Kyvik, 2012). Strikingly, Malaysian full professors spent significantly fewer hours on research (30 percent) than lower ranked staff. Holding a $\mathrm{PhD}$ was also a weak predictor of 
additional research hours, except in Canada where it was the second-strongest variable and associated with a 39 percent increase in research hours. Statistically significant positive effects were also found in Argentina and Australia.

The status criterion with the strongest relationship with research hours was ones relative level of publication performance. A high level of publishing (in the top quartile of faculty) was associated with significant increases in research hours in the UK (33 percent) and Australia (27 percent). However, a low level of publishing (bottom quartile) had a stronger association with research hours, with significant negative relationships found in Hong Kong, Brazil, USA, China and Canada, and to a lesser extent in Australia, UK and Italy. We can not imply from these results that status criteria have a strong role in university research time allocations, but it does appear that individual faculty with demonstrated research competence do manage to find additional hours for this activity.

Results for Sacred spark theory

The greater inner compulsion that some faculty have towards research, referred to as the “sacred spark” theory (Cole and Cole 1973), received the strongest support from our result in explaining why some faculty dedicate more time to research than others. Across all thirteen countries, faculty who reported a stronger interest in research (relative to teaching) spent significantly more hours on research. A one-unit increase in research interest relative to teaching, was associated with roughly 25 percent more research hours in most countries. These results are similar to Gottlieb and Keith (1997) who found research interest was associated with five extra hours of research. Although clearly the variable with the most 
consistent relationship with research hours, academic field had a stronger relationship in China, Italy and Brazil.

The proportion of one's teaching load dedicated to teaching doctoral researchers (as opposed to undergraduate, masters or other teaching programs) was not a strong predictor of research hours, but was significant in Brazil and Argentina, and to a lesser extent in Australia, Finland and Germany. In the case of Brazil, it was the strongest variable associated with research hours. In all cases, doctoral teaching was positively related to research hours.

Results for Utility maximizing theory

The utility maximizing theory suggests that individual faculty research time partly reflects rational choices seeking greater income, prestige or intrinsic outcomes (Stephan and Levin 1992). Three variables were operationalized to investigate this theory: age; age squared; the extent to which one’s institution emphasizes research quality when making personnel decisions; and permanency/tenure.

Before discussing the regression results, it is worth briefly discussing the interaction between age (or career stage) and academic field. As noted by Becher (1989), mid-career 'burn out' and inertia is more common in scientific disciplines with cumulative knowledge-bases, while 'late-bloomers' may be more common in softer disciplines of the humanities and social sciences where knowledge is contested. Figure 1 illustrates the bi-variate relationship between research hours and age in the five academic fields. Although age has a broadly negative and linear relationship with research hours in most academic fields, there is no such relationship in the humanities. The second noticeable trend is that research hours generally 
increase in the oldest age group (over 60 years), particularly in the humanities where this age group has the highest mean research hours.

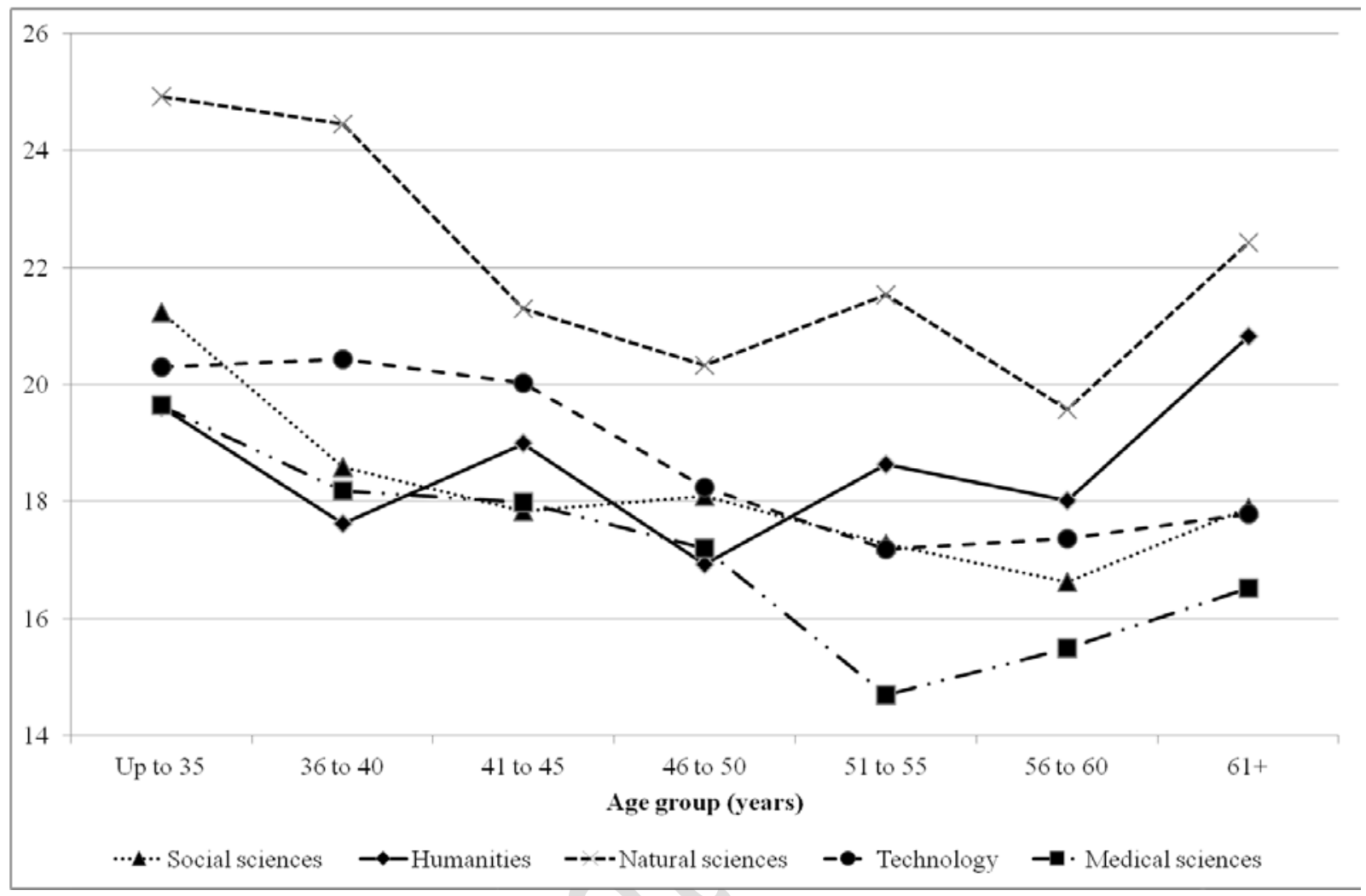

Figure 1. Mean Research Hours by Age Group and Academic Field

In Figure 1, the uniqueness of humanities may reflect its non-cumulative knowledge structure. We investigated this further by adding interaction variables for academic field and age, and academic field and age squared. We recomputed all OLS regressions and included the eight interaction variables, taking social sciences as the reference group. The interactions were mostly insignificant ( $p>0.05)$ or were very weak. The exception was Norway where, and to a lesser extent in the USA, where the interaction between age and humanities was significant and positive (but not age squared). This implied that the generally negative linear relationship between age and research hours did not apply in the humanities in these countries. Other smaller but statistically significant $(p<0.05)$ and negative interactions were found for age and natural sciences in Italy and Australia, age and medicine in Italy, and age 
squared and natural sciences and Canada. Overall, the weak results suggested that faculty in the natural sciences were not unique in being 'burnt-out' or seeing research decline in older age cohorts, but 'late bloomers' in humanities received support in Norway.

Returning to our regression results in Table 3, we found that age exhibited a significant relationship with research hours in six countries. One additional year was associated with one percent fewer research hours in Argentina, Canada, UK and USA. The positive and significant beta coefficients for age squared in Argentina, Hong Kong, Italy, UK and USA, indicate that the decline in research hours with age may be alleviated by a late-career increase amongst the oldest age groups. The influence of a continuous employment contract (tenure) was not significant, except in Australia, and to a lesser extent Argentina and Canada, all of which suggested a negative relationship with research hours. Utility maximization theory would suggest that when research quality is included in university personnel decisions, individual faculty would have a stronger incentive to dedicate time to this activity. However, in most countries this variable was weak and insignificant, with the notable exceptions of Argentina and Italy where, contrary to expectations, agreement was associated with fewer research hours.

Results for Differences in family commitments

Gender was insignificant in all countries other than Malaysia, where males spent roughly 20 percent more hours on research. and in Australia where the results were very weak. The presence of children in the home had minimal relationship with research hours, with no discernible pattern emerging. We also tested for interactions between gender and children in the home, with the expectation that females with children may exhibit a stronger negative 
relationship with research hours, but the OLS regression results for the interaction variables were overwhelmingly insignificant in each of the 13 countries.

Results for Academic field effects

When compared to faculty in the humanities, most of the academic field differences were insignificant. However, academic field was one of the strongest predictors of research hours in Brazil, Italy and Malaysia, and faculty in technology disciplines tended to spend more hours on research.

\section{Discussion}

Faculty have long been attracted to academic work for the relatively strong autonomy it provides to pursue one's research interests, communicate ideas to disciplinary colleagues and transfer knowledge to students and future researchers (Bellamy et al. 2003) . While there are undeniable tensions between academic autonomy and managerial control over working time, our results suggest that an individual's level of interest in research is the strongest predictor of one's research time allocation. Consistently across all 13 countries, we found that faculty primarily or mostly interested in research spent significantly more hours on research than their teaching oriented colleagues. This was the case even after controlling for the effects of research qualifications, previous publications research funding and other factors one may associate with highly motivated researchers. In other words, some faculty have a stronger inner compulsion to do research and such faculty manage to find extra hours for this activity. This supports the "sacred spark" theory that individual faculty differ in their abilities and 
motivations towards research (Cole and Cole 1973) and is consistent with Gottlieb and Keith’s (1997) earlier international study.

However, the statistical significance of research motivation was weaker in China. This may be due to the lingering effects of the traditional bureaucratic management of faculty work, which treated faculty uniformly regardless of research performance. According to Chen (2003), changes in the governance and management of Chinese universities since the 1990s have led to a transition from a highly bureaucratized "title system" of tenure based on length of service with minimal incentives to work hard, to a more flexible, individualistic and competitive system, drawing heavily on practices in the USA. Under the former system, many highly motivated and talented researchers were enticed away from research into administrative positions which offered greater power and status.

The generally weak relationships between research time and most other independent variables suggest that research locations have little to do with university policies and status criteria. The exception was the Australian sample, where a consistent pattern amongst the independent variables emerged in the hypothesized directions. Australian faculty who received a large proportion of their research funding from non-institutional sources, found significantly more time for research. The same can be said for those faculty members who had the highest levels of publishing, while having a low level of publishing was likewise associated with significantly fewer research hours. Similar patterns were evident in the UK and to a lesser extent, Hong Kong. While we expected a stronger relationship between individual research time and these variables in other countries, the fact that these variables are most significant in Australia may be explained by the steep academic hierarchy and 
entrenched nature of managerial practices promoting individualism and stratification (Lafferty and Fleming 2000).

Declining government funding leave universities more dependent on external research funding, and while all faculty teach, external research funding is a key distinguisher between individual faculty members (Slaughter and Leslie 1997). When time pressures are particularly acute, external research funding can be the only method for faculty to "buy themselves out" of other duties and free up time for research (Barry, et al. 2003). The greater statistical significance of the university allocation variables in Australia is consistent with Slaughter and Leslie’s (1997) results, which showed market mechanisms for resource allocation more advanced in Australian universities compared to USA and the UK. By contrast, Canadian faculty were yet to experience managerial oversight to the same extent, which is also consistent with our results. Doctoral qualifications were more strongly associated with research hours in Canadian universities than other factors, such as publication productivity. The greater importance of external research funding and publishing in Australian universities suggests that competitive performance-based processes are more important status criteria for research time allocations than qualifications.

Our results for gender and children responsibilities were insignificant in most countries, but one must also be cautious not to dismiss the indirect influence of these variables on research time. Our sample excluded part-time faculty and it is likely that women with caring responsibilities may opt out of full-time academic employment given the well-documented difficulties managing competing demands (Barry, et al. 2003; Jacobs and Winslow 2004a; 2004b; Probert 2005).Therefore, the remaining group of full-time female academics with young children may not be representative of the population of academics caring for children. 
Many of the fixed-standard variables also minimize the effect of these variables, as research publishing is affected by dependent children (Kyvik and Teigen 1996).

The data on American faculty warrants further scrutiny because USA is a country where we have previous multivariate studies of research time. Bellas and Toutkoushian (1999) examined time allocations between tasks and found full professorship positively associated with the proportion of time dedicated to research, while females and lecturers spent relatively more time on teaching. Link and colleagues' (2008) explored the role of tenure and promotion in determining the number of research hours, controlling for gender, ethnicity, citizenship and marriage. They found research hours declined with promotion to associate professor and with the number of years of tenure, particularly beyond 7 years of tenure.

Although we do not find a significant relationship between tenure and research hours in our regression results, we do find similar results for rank and length of time since promotion. Assistant professors and other junior faculty averaged 19.7 research hours per week $(n=182)$ and full professors 20.3 hours, compared to 16.1 hours for associate professors. Associate professors with seven or more years at this rank spent fewer hours on research (13.5 hours, $n=56$ ) compared to other associate professors (167 hours, $n=129$ ). This provides some support to Link and colleagues'(2008) assertions that tenure and length of time as an associate professor may be associated with fewer research hours. However, it is not clear if this is due to declining preferences towards research, the perceived utility of additional research or other factors.

\section{Conclusion}


Using data from a survey of university faculty across 13 different countries, our analysis showed significant variation in the number of hours devoted to research within and between countries. We examined three different groups of explanations for variation between individual faculty members, differences in: (a) university policy, (b) individual motivation, and (c) family commitments. While each of these three explanations can account for a significant proportion of the variation in research hours in Australia, in most countries the relationships are weak. A strong individual motivation towards research over teaching was the only variable which showed a significant and positive relationship with research hours in all 13 countries. This lent the strongest support for the "sacred spark" theory that certain faculty prioritize and have an inner compulsion to do research. The significance of this variable, compared to university allocation policies, may also be reassuring to those concerned about the state of faculty autonomy. However, research hours vary considerably within each of our national samples and our model generally explained only a small fraction of this variation. Even though this is similar to former studies of research time allocation (Gottlieb and Keith 1997, Bellas and Toutkoushian 1999, Link et al. 2008), much remains to be explained as to why research hours vary so dramatically between faculty.

One reason why university allocation policies did not explain much of the variation in research hours may be that unequal resource distribution conflicts with prevailing academic norms for formal equality amongst faculty staff. In addition to strategic objectives and practical considerations, resource allocation policies are also influenced by considerations on distributional justice (Elster 1992; Kyvik 2009). Research time is also prerequisite for developing research competence, and concentrating research time allocations towards certain faculty may not maximize the research potential of the entire staff base. Such practices may 
also conflict with political objectives to extend research opportunities to historically underrepresented groups.

Another reason may be that university managers have weak power to implement policies. This could also account for some of the differences we noticed across countries. For example, in Brazil the top-tier universities have strong collegial power and been able to resist changing in response to government policy or administration objectives (Balbachevsky and Quinteiro 2003). By contrast, the Argentine Government's modernization agenda of the early 2000s required faculty to improve their research skills, which led to en mass enrolment in postgraduate degrees (Marquis 2003). In Argentina, faculty are highly stratified based on research qualifications and there are very few full-time faculty actively engaged in both research and teaching. The significance of the $\mathrm{PhD}$ as a factor associated with research hours in Argentina may reflect the relatively stronger role of a $\mathrm{PhD}$ in this system. By comparison, in the $\mathrm{UK}$, Hong Kong and Australia, where the PhD is largely a pre-requisite for entry, government policies and research funding agencies have focused on assessing quality and quantity of research.

Finally, our results also suggest that academic field remains an important factor when understanding the diversity in faculty research hours. Generally, those employed within technology and engineering departments spent more hours on research, which may reflect the ability of such academics to bypass institutional constraints on research funding. Faculty within the medical sciences also tended to be less engaged with research, but this may be due to how universities accommodate external service into academic duties. The concept of “individual freedom” is broadly interpreted in Italian universities and research time is 
considerably less in medicine and other professional fields where faculty are able to maintain full-time faculty appointment while actively engaging in external service (Moscati 2001).

\section{References}

Balbachevsky, E., \& Quinteiro, M. C., 2003. The changing academic workplace in Brazil. In P. G. Altbach (Ed.), The Decline of the Guru: The Academic Profession in Developing and Middle-Income Countries (pp. 75-106). New York: PalgraveMacmillan.

Barry, J., Berg, E., \& Chandler, J. (2003). Managing intellectual labour in Sweden and England. Cross Cultural Management: An International Journal, 10(3), 3-22.

Becher, T. (1989). Academic Tribes and Territories. Intellectual Enquiry and the Culture of Disciplines. Milton Keynes: Open University Press.

Bellamy, S., Morley, C., \& Watty, K. (2003). Why business academics remain in Australian universities despite deteriorating working conditions and reduced job satisfaction: an intellectual puzzle. Journal of Higher Education Policy and Management, 25(1), 1328.

Bellas, M. L., \& Toutkoushian, R. K. (1999). Faculty time allocations and research productivity: Gender, race, and family effects. Review of Higher Education, 22, 367390.

Bentley, P. J., \& Kyvik, S. (2012). Academic work from a comparative perspective: a survey of faculty working time across 13 countries. Higher Education, 63, 529-547.

Cole, J. R., \& Cole, S. (1973). Social Stratification in Science. Chicago: University of Chicago Press. 
Chen, X. (2003). The Academic Profession in China. In P. G. Altbach (Ed.), The Decline of the Guru: The Academic Profession in Developing and Middle-Income Countries (pp. 107-134). New York: Palgrave-Macmillan.

Guest, R., \& Duhs, A. (2002). Economics teaching in Australian universities: rewards and outcomes. Economic Record, 78(241), 147-160.

Elster, J. (1992) Local Justice: How Institutions Allocate Scarce Goods and Necessary Burdens. Cambridge: Cambridge University Press.

Enders, J. (Ed.). (2001). Academic Staff in Europe: Changing Contexts and Conditions. Westport: Greenwood Press.

Enders, J., \& Teichler, U. (1997). A victim of their own success? Employment and working conditions of academic staff in comparative perspective. Higher Education, 34(3), 347-372.

Hood, C. (1995). The" new public management" in the 1980s: Variations on a theme. Accounting Organisations and Society, 20, 93-109.

Jacobs, J. A. (1998). Measuring time at work: are self-reports accurate? Monthly Labor Review, 121(12), 42-53.

Jacobs, J. A. (2004). The faculty time divide. Sociological Forum, 19(1), 3-27.

Jacobs, J. A., \& Winslow, S. E. (2004a). The academic life course, time pressures and gender inequality. Community, Work \& Family, 7(2), 143-161.

Jacobs, J. A., \& Winslow, S. E. (2004b). Overworked faculty: Job stresses and family demands. The ANNALS of the American Academy of Political and Social Science, 596(1), 104-129.

Kyvik, S. (2009). Allocating Time Resources for Research between Academic Staff: The Case of Norwegian University Colleges. Higher Education Management and Policy 21(3), 109-122. 
Kyvik, S. (2012). Academic salaries in Norway: Increasing emphasis on research achievement. In P.G. Altbach, L. Reisberg, M. Yudkevich, L. Reisberg, G. Androushchak \& I. Pacheco (eds.), Paying the Professoriate. (pp. 255-264). New York: Routledge.

Kyvik, S., \& Olsen, T.B. (2008). Does the aging of tenured academic staff affect the research performance of universities? Scientometrics, 76(3), 439-455.

Kyvik, S., \& Teigen, M. (1996). Child care, research collaboration, and gender differences in scientific productivity. Science, Technology, \& Human Values, 21(1), 54-71.

Lafferty, G., \& Fleming, J. (2000). The restructuring of academic work in Australia: Power, management and gender. British Journal of Sociology of Education, 21(2), 257-267.

Link, A., Swann, C., \& Bozeman, B. (2008). A time allocation study of university faculty. Economics of Education Review, 27(4), 363-374

Long, J. (1990). The origins of sex differences in science. Social Forces, 68(4), 1297-1316. Marquis, C. (2002) Universities and professors in Argentina: Changes and challenges. In P. G. Altbach (Ed.), The Decline of the Guru: The Academic Profession in Developing and Middle-Income Countries (pp. 51-74). New York: Palgrave-Macmillan.

Massy, W. F., \& Zemsky, R. (1994). Faculty discretionary time: Departments and the" academic ratchet." Journal of Higher Education, 65(1), 1-22.

Meyer, K. A. (1998). Faculty workload studies: Perspectives, needs, and future directions. ASHE-ERIC Higher Education Report No. 1. Washington, DC: George Washington University, Graduate School of Education and Human Development.

Probert, B. (2005). 'I just couldn't fit it in': Gender and unequal outcomes in academic careers. Gender, Work \& Organization, 12(1), 50-72.

Robinson, J. P., \& Bostrom, A. (1994). The overestimated workweek? What time diary measures suggest. Monthly Labor Review, 111(8), 11-23. 
Rosser, V. J., \& Tabata, L. N. (2010). An examination of faculty work: Conceptual and theoretical frameworks in the literature. In J. C. Smart (Ed.), Higher Education: Handbook of Theory and Research (Vol. 25, pp. 449-475). Dordrecht: Springer.

Sax, L., Hagedorn, L., Arredondo, M., \& DiCrisi, F. (2002). Faculty research productivity: exploring the role of gender and family-related factors. Research in Higher Education, 43(4), 423-446.

Slaughter, S., \& Leslie, L. L. (1997). Academic Capitalism: Politics, Policies, and the Entrepreneurial University. Baltimore: The Johns Hopkins University Press.

Stephan, P. E., \& Levin, S. G. (1992). Striking the Mother Lode in Science: The Importance of Age, Place, and Time. New York: Oxford University Press.

Teichler, U. (2008) 'Academic Sstaff in Germany: per aspera ad astra?', In Changing Academic Profession in International Comparative and Quantitative Perspectives (pp. 131-152). Hiroshima: RIHE Hiroshima University.

Teodorescu, D. (2000) Correlates of faculty publication productivity: A cross-national analysis, Higher Education 39(2): 201-222.

UNESCO. (1978). Recommendation Concerning the International Standardization of Statistics on Science and Technology. Paris: UNESCO.

White, K. (2001) 'Women in the Professoriate in Australia', International Journal of Organisational Behaviour 3(2): 64-76.

White, K. (2004). The leaking pipeline: Women postgraduate and early career researchers in Australia. Tertiary Education and Management, 10(3), 227-241.

Ylijoki, O.-H. (2003) 'Entangled in academic capitalism? A case-study on changing Idieals and practices of university research', Higher Education 45(3), 307-335. 
Zemsky, R., Wegner, G. R., \& Massy, W. F. (2005). The Lattice and the Ratchet. In R.

Zemsky, G. R. Wegner \& W. F. Massy (Eds.), Remaking the American University: Market-smart and Mission-centered (pp. 15-31): Rutgers University Press. 


\section{University Library}

\section{- M M N E R VA A gateway to Melbourne's research publications}

Minerva Access is the Institutional Repository of The University of Melbourne

Author/s:

Bentley, PJ;Kyvik, S

Title:

Individual Differences in Faculty Research Time Allocations Across 13 Countries

Date:

2013-05-01

Citation:

Bentley, P. J. \& Kyvik, S. (2013). Individual Differences in Faculty Research Time Allocations Across 13 Countries. RESEARCH IN HIGHER EDUCATION, 54 (3), pp.329-348. https:// doi.org/10.1007/s11162-012-9273-4.

Persistent Link:

http://hdl.handle.net/11343/113918 